Durrieu et al. Quantification of nuclear transport in single cells

\title{
Quantification of nuclear transport in single cells
}

Durrieu, Lucía ${ }^{1,2}$; Johansson, Rikard ${ }^{3}$; Bush, Alan ${ }^{1}$; Janzén, David ${ }^{3,4}$; Gollvik, Martin $^{3}$; Cedersund, Gunnar ${ }^{3,5}$; and Colman-Lerner, Alejandro'.

1- Institute of Physiology, Molecular Biology and Neurosciences, National Research Council and Department of Physiology, Molecular and Cell Biology, School of Exact and Natural Sciences, University of Buenos Aires, Buenos Aires, Argentina.

2- Present addresses: EMBL Heidelberg, Heidelberg, Germany; Zentrum für Molekulare Biologie der Universität Heidelberg, Deutsches Krebsforschungszentrum, DKFZ-ZMBH Allianz, Heidelberg, Germany.

3- Department of Biomedical Engineering, Linköping University, Linköping, Sweden.

4- Present addresses: Biomedical and Biological Systems Laboratory, School of Engineering, University of Warwick, Coventry, UK; AstraZeneca, Mölndal, Sweden; Department of Systems and Data Analysis, Fraunhofer-Chalmers Centre, Gothenburg, Sweden.

5- Department of Clinical and Experimental Medicine, Linköping University, Linköping, Sweden.

Correspondence to: Alejandro Colman-Lerner, colman-lerner@fbmc.fcen.uba.ar

Abstract

Regulation of nuclear transport is a key cellular function involved in many central processes, such as gene expression regulation and signal transduction. Rates of protein movement between cellular compartments can be measured by FRAP. However, no standard and reliable methods to calculate transport rates exist. Here we introduce a method to extract import and export rates, suitable for noisy single cell data. This method consists of microscope procedures, routines for data processing, an ODE model to fit to the data, and algorithms for parameter optimization and error estimation.

Using this method, we successfully measured import and export rates in individual yeast. For YFP, average transport rates were $0.15 \mathrm{sec}^{-1}$. We estimated confidence intervals for these parameters through likelihood profile analysis. We found large cell-to-cell variation 
$(\mathrm{CV}=0.79)$ in these rates, suggesting a hitherto unknown source of cellular heterogeneity. Given the passive nature of YFP diffusion, we attribute this variation to large differences among cells in the number or quality of nuclear pores.

Owing to its broad applicability and sensitivity, this method will allow deeper mechanistic insight into nuclear transport processes and into the largely unstudied cell-to-cell variation in kinetic rates.

\section{Introduction}

Regulation of nuclear transport is a key cellular function involved in many central processes, such as gene expression regulation and signal transduction. Localization of a protein to the nucleus has some obvious consequences. For signaling proteins, compartmentalization can improve signal transduction efficiency and specificity by raising its local concentration, and by helping it to interact with its targets. For transcription factors, localization to or out of the nucleus has been shown repeatedly as a mechanism for regulation of the gene expression (Görner et al., 1999; Komeili and O'Shea, 2000; Lee and Hannink, 2003; Chu et al., 2007; Poon and Jans, 2005; O’Brate and Giannakakou, 2003). These regulatory opportunities are given only by the differential localization of proteins. There are, however, more subtle properties of nuclear transport. Nuclear localization of a protein may be achieved by static or dynamic mechanisms. That is, the protein maybe trapped in the nucleus (due to binding to other macromolecules or simply because it is not exported), or it might shuttle continuously between the nucleus and the cytosol with faster import than export (Chu et al., 2007). The functional relevance of this difference becomes clear if we consider that the protein might suffer modifications in one compartment that affect its function in the other compartment.

Molecules exchange between the nucleus and the cytosol occurs through nuclear pore complexes (NPCs), which are 66 MDa complexes embedded in the nuclear envelope. The yeast nuclear pore is composed of 30 different nucleoporines (nups) (Rout et al., 2000). Passage of material can occur in two ways: passive diffusion for small molecules (up to 40 $\mathrm{kDa}$ (Paine and Scherr, 1975) or $~ 5 \mathrm{~nm}$ diameter(Yang and Musser, 2006; Mohr et al., 2009),or facilitated translocation for bigger species(Ribbeck and Gorlich, 2001). In contrast to passive diffusion, facilitated transport is coupled to the transport of the small GTPase Ran, enabling net movement of cargoes against their chemical gradient through the dissipation of the primary gradient of Ran-GTP. Facilitated translocation requires specific interactions between the translocating species and constituents of the NPC and is therefore a highly selective and regulated process.

The superfamily of importin Beta-related factors constitutes the best-characterized class of nuclear factors so far. According to the direction in which they carry a cargo, they can be classified as importins or exportins. The cargo-receptor interactions are controlled by the Ran-GTP gradient across the nuclear envelope. Importins bind cargoes at low Ran-GTP 
levels in the cytoplasm and release their cargo at high Ran-GTP concentrations into the nucleus. Exportins do the opposite (Becskei and Mattaj, 2005).

Many models of nuclear pores have been proposed (reviewed in (Kahms et al., 2011)). Most of them consider that the selectivity of the NPC depends on the FG-repeat domains of the nups. These are naturally unfolded phenylalanine -glycine rich domains that are present in almost $30 \%$ of the nups. The conformation of the FG domains in vivo, their arrangement in relation to the transport channel and their consequences for transport are still in discussion and more functional data regarding the mechanism of the NPC is needed.

Understanding of the complex and highly dynamic processes that take place inside cells, and discerning between different models for these processes, such as regulation of protein localization and NPC structure, requires computational methods that integrate quantitative measurements with mathematical models. Accurate experimentally determined rate constants are crucial to build and test such models. Nuclear import rates have been estimated in in vitro essays. In some of these essays, the plasma membrane is first permeabilized, then transport factors and fluorescently-labeled cargoes are added, and the increase in fluorescence in the nucleus is measured over time(Yang et al., 2004; Ribbeck and Gorlich, 2001) or nuclear transport rates are measured in single-molecule experiments performed by narrow-field microscopy (Kubitscheck et al., 2005; Yang et al., 2004). Import rates have also been determined for Xenopus oocytes using nuclear membranes or isolated intact nuclei (Keminer and Peters, 1999; Keminer et al., 1999; Siebrasse and Peters, 2002). Although very valuable, all of these experiments rely on the use of cells with altered cytoplasms where the transport machinery is externally added, and, in addition, do not allow the determination of export rates. An in vivo essay for estimation of import rates is based in the microinjection of labeled cargoes into intact cells (Riddick and Macara, 2005). However, this method uses external cargoes and is not suited for all types of cells, since microinjection of small cells is very difficult. Another assay for the determination of import rates in living cells, developed in yeast, is based on measuring the relaxation of the system after a perturbation (Timney et al., 2006). In cells with a fluorescently tagged protein, transport is stopped by the addition of metabolic energy poisons, which dissipate the RanGTP gradient. Then, these blockers are washed, and nuclear fluorescence is quantified, as the gradient is re-established. This method has the disadvantage that the use of an energy poison is a very strong, non-specific alteration of the cellular homeostasis.

Transport between cellular compartments in vivo can be studied using the techniques known as fluorescence recovery after photobleaching (FRAP) and fluorescence loss in photobleaching (FLIP). In both approaches a perturbation is introduced by bleaching a small area of a cell expressing a fluorescent protein. In FRAP, the bleached region is monitored as unbleached molecules move into it, resulting in an increase (recovery) of the fluorescence level. In FLIP, another-unbleached-, region is monitored, as its fluorophores are exchanged by bleached fluorophores moving from the bleached region, resulting in a reduction (loss) of the initial fluorescence level. The data obtained with these experiments is usually fitted to an exponential curve that does not immediately inform about the more 
biologically meaningful import and export rates. Actual transport rates have been determined in intact cells, but only for over-expressed cargoes (Cardarelli et al., 2009, 2011; Bizzarri et al., 2012), or under assumptions that are not valid for every system, such as infinite size cytosol (Gregor et al., 2007), or equilibrium between compartments (Pfeifer et al., 2010). Furthermore, with the exception of a few recent publications (Cardarelli et al., 2012; Pfeifer et al., 2010; Cardarelli et al., 2009, 2011), all published data we found corresponds to population averages (see for example (Sprague and McNally, 2005; Fonseca et al., 2012; Huranová et al., 2010; Sekiya et al., 2009; Rino et al., 2008; Molenaar et al., 2004; Shav-Tal et al., 2004)) .

One of the most important developments in cell biology during the last decade has been the increased focus on single cells. Cell-to-cell variability plays an important role in cell fate decisions. Thus, to achieve a system-level understanding of cellular function it is essential to have quantitative measurements of dynamic processes in single cells. Remarkably, several single cells studies have revealed that single -cell behavior differs substantially from what was originally inferred from previous population studies and identified nongenetic sources of cellular heterogeneity (Spencer et al., 2009; Colman-Lerner et al., 2005). Therefore, inclusion of cell-to-cell variability is a natural next step for kinetic modeling.

Herein, we present a new approach to the analysis of FRAPs, focused on determining kinetic parameters for single yeast cells. We show that the noisy nature of single cell determinations can be surmounted by performing series instead of single FRAPs on the same cell. Furthermore, our model analysis and experimental investigations demonstrated that a two-dimensional ODE-based model is sufficiently realistic to describe such a series of FRAPs accurately, and that it yields reliable parameters. Using this method, we found large cell-to-cell variation in nuclear transport rates for YFP, revealing that the number and or quality of nuclear pores might be a hitherto unsuspected source of functional cellular heterogeneity.

Results

\section{Nuclear transport rates determination}

To determine accurately the nuclear transport rates in single cells we needed (i) a kinetic model to fit to the data that represented our knowledge of the system, with parameters that were both identifiable and related to the kinetic transport rates, (ii) a microscopy protocol to obtain high quality FRAP data, (iii) an algorithm for quantification, correction and processing of images, (iv) an optimization algorithm to find the best fit, and (v) a method for the estimation of the errors of the fittings.

\section{Model selection}

The raw data obtained from any FRAP experiment only indicates whether the protein is shuttling in and out of the bleached region. To extract numbers, one needs a mathematical model to fit to the experimental data. For this purpose, we wrote an ODEs model in which 
the inward and outward fluxes depend linearly on the nuclear and cytosolic fluorescent protein concentrations. In the model, $\mathrm{n}$ is the number of fluorescent molecules in the nucleus, $\mathrm{c}$ is the number of fluorescent molecules in the cytosol, $\mathrm{k}_{\mathrm{I}}$ is the import rate and $\mathrm{k}_{\mathrm{EV}}$ is the export rate multiplied by the ratio of cytoplasmic and nuclear accessible volumes (the volume through which the molecules can diffuse). With these notations, the model is given by (box 1)

$$
\begin{array}{ll}
\mathrm{dn} / \mathrm{dt}= & -\mathrm{n} \mathrm{k}_{\mathrm{EV}}+\mathrm{c} \mathrm{k}_{\mathrm{I}} \\
\mathrm{dc} / \mathrm{dt}= & \mathrm{n} \mathrm{k}_{\mathrm{EV}}-\mathrm{c} \mathrm{k} \mathrm{k}_{\mathrm{I}}
\end{array}
$$

The model (1) depends on a number of assumptions. For instance, it is assumed that the fluxes before the FRAP have reached steady-state. Interestingly, this steady-state assumption means that the linear kinetics follows by necessity (Box 1). Another assumption behind the model is that the cytosol and the nucleus can be considered as well-stirred compartments, and this assumption is supported by three arguments. The first argument is based on photobleaching completely a small area ( $\sim 0.5$ micron diameter) of a given compartment and then imaging the cell to determine how fast the bleached area recovered its original fluorescence level. Both in the nucleus and in the cytosol this time was less than $1 \mathrm{sec}$, but it took at least $5 \mathrm{sec}$ to reach steady state between compartments (Fig S1). The second argument is based on a theoretical approach, where we estimated the time scale for diffusion by dimensional analysis. We calculated the time that it would take a protein to diffuse a given distance " $r$ " as the ratio between $r^{2}$ and the diffusion coefficient for that protein. For a small protein like YFP (27 kDa), this calculation gives $5 \mathrm{~ms}$ to diffuse $2.5 \mu \mathrm{m}$ (half the radius of an average yeast cell); for a bigger protein of $\sim 86.5 \mathrm{kDa}$ ) it would take $50 \mathrm{~ms}$, still significantly faster than the estimated transport between compartments. The third argument is based on a comparison of other model-structures, where the cytosol was divided in 2 to 5 concentric shell-like compartments (like layers of an onion) (see sup mat). For none of these models we found a significant improvement on the fits than the simpler model (Fig SM1). Thus, taken together, the above arguments suggest that the main assumptions behind the model are reasonable.

\section{Experimental design}

In a FRAP protocol most decisions imply tradeoffs: for example, a fast scanning will lead to high time resolution but also to high noise. To define an optimal microscopy protocol, we performed a theoretical analysis in which we simulated data of different characteristics and then analyzed the accuracy of the fitted rates (see sup mat). We concluded that it is preferable to increase time resolution even at the cost of increasing the noise. However, noise can be problematic when it is high relative to the signal (Fig S2). To cope with this problem, we decided to perform several, sequential FRAPs in each nucleus ("trains of FRAPs") (Fig 1a). This type of approach reduces the noise without affecting the time 
resolution. An obvious advantage of performing more than one FRAP is to increase the number repetitions, which we could average (after normalizing) to obtain a FRAP with lower noise. In addition, we reasoned that if we fit trains of FRAPs directly as obtained -as a multiple perturbation FRAP- instead of averaging, we could have the extra advantage of decreasing the interdependence of the measured variables (i.e. nuclear and cytosolic amounts of fluorescent proteins). This is because after each individual FRAP in the train, the total amount of fluorescent proteins available for the next FRAP would change independently ( $\mathbf{n}$ and $\mathbf{c}$ in the above analysis). To test these ideas we simulated data of trains of 1 to 5 FRAPs, using a range of realistic parameters and added different levels of white noise. We used additive noise because it is what we expect from the microscope data (Gordon et al., 2007). We fitted this simulated, noisy, data as described below for the experimental data. As expected, increasing the number of FRAPs improves the parameter accuracy when the data is noisy. Notably, trains of only 4 FRAPs resulted in parameter fits consistently close to the true value with signal to noise ratios as low as 5 (Fig 1b). Interestingly, for every noise level tested, the biggest improvement was obtained by doing trains of two FRAPs instead of one. Finally, we tested whether fitting the non-normalized train of FRAPs data had an advantage over fitting the average of the normalized FRAPs and found that this is slightly better (Fig 1c).

\section{Parameters optimization and evaluation}

We fitted the simulations to the data by finding those parameters that minimize the deviations between data and simulations (Materials and Methods). In Figure 2, we illustrate the different parts of the process, based on data from one of the cells. In Fig $2 \mathrm{a}$, we show the first FRAP of a typical four FRAP experiment. For the parameter optimization, we used a chi-square cost function and established a threshold ( $p=0.95$ and two degrees of freedom in an inverse chi-squared test) for the cost under which all parameter pairs were "acceptable" (red points in Fig 2b). For the shown cell, the best values of $\mathrm{k}_{\mathrm{EV}}$ and $\mathrm{k}_{\mathrm{I}}$ were $0.412 \mathrm{~s}^{-1}$ and $\mathrm{kI}$ $0.035 \mathrm{~s}^{-1}$, respectively (blue diamond in Fig $2 \mathrm{~b}$ and blue line in Fig 2c). Next, we tested whether the amount and quality of the experimental data were enough for the two parameters to be identifiable (i.e., if they could be determined independently from each other with finite errors). We performed this analysis by exploiting the likelihood profile, and found that the parameters were identifiable (Fig 2d). This method also gave us confidence intervals for the parameters, which were around $10 \%$ of the value (Fig $2 \mathrm{~d}$ ).

\section{Passive transport rates in single cells}

We determined the rate of diffusion across the pores for YFP in single yeast cells using the method presented above. In these measurements, we wanted to minimize potential variation due to the cell cycle, but, at the same time, we wanted to avoid the interventions required to synchronize cultures. Consequently, we restricted our measurements to cells passing the first part of G1, operationally defined by the localization of two marker proteins. First, we marked the actomyosin ring, which disappears when cells complete cytokinesis, tagging one of its components, Myo1, with mCherry. Second, we marked late M/early G1 nuclei transforming cells with a plasmid containing a CFP-Ace2 fusion controlled by its own 
promoter. The transcription factor Ace 2 translocates to the nucleus at the end of mitosis and remains nuclear during early G1 (Dohrmann et al., 1992; Colman-Lerner et al., 2001; Weiss et al., 2002). For all measurements, we used cells with nuclear Ace 2 and no visible actomyosin ring.

Since YFP does not interact with any importin or exportin and it is small enough to diffuse passively through the nuclear pores, its import and export should have the same rate. We found that in the strain BY4741 this rate was, on average, $0.12 \mathrm{sec}^{-1}$ (Figure 3a). We obtained similar values in another commonly used yeast strain, W303 (Figure 3b). This value means that if a protein has an abundance of 2460 (the mode of protein abundance in budding yeast estimated by Wagner et al(2005)), approximately 295 molecules of this protein will enter (and leave) the nucleus per second.

Interestingly, we found a rather large cell-to-cell variation in the transport rate for YFP $(\mathrm{CV}=0.93)$ (Figure 3a-b and Figure S3-with individual fits). Since YFP passage through the NPC does not require binding to any factors, cell to cell variation in this rate most likely reflects cell to cell differences in the number of NPCs or in their quality (allowing more or less diffusion of YFP). We studied the relationship between the initial fluorescence concentration and our fitted parameters and found, as expected for a freely diffusing molecule, that the rates do not correlate with total YFP fluorescence (Figure 3c).

\section{Cytosol- nucleosol diffusion-available volumes ratio (V)}

From the FRAP analysis we obtained the parameter $\mathrm{k}_{\mathrm{EV}}$, the export rate multiplied by $\mathbf{V}$, the ratio of the diffusion accessible volumes of the cytosol and the nucleosol. Thus, in general, to determine export rates, one needs to determine $\mathbf{V}$. This value is of interest in itself, and it should be different from the ratio of the cytoplasm to the nucleus volume, since not all of the cytoplasmic and nuclear volumes are available for diffusion, due to the presence of organelles, macromolecules and chromatin, and, in general, other cellular material that occupies space. Because, as explained above, import and export rates for YFP should be the same, $\mathbf{V}$ is just the ratio between the $\mathbf{k}_{\mathbf{E V}}$ and $\mathbf{k}_{\mathbf{I}}$ values obtained from the fitting of the FRAP experiments using untagged YFP. Our results indicate an average $\mathbf{V}$ of 4.77 and a CV of 0.20 (Figure 4); that is, the effective volume in the cytosol available for diffusion in 4.77 times larger than that volume in the nucleosol. This value is noteworthy, since the nucleus is approximately 14 times smaller than the cell, as determined using geometrical considerations only (Jorgensen et al., 2007). We wondered whether this proportion between the nucleosol and cytosol volumes could depend on the strain background, so we performed the same measurement in a W303 strain, and obtained remarkably similar values (Figure 4). This is expected in the light of previous studies (Webster et al., 2010; Jorgensen et al., 2007) that reported that the geometrically determined nucleus/cell volumes ratio is constant in various circumstances. Also in agreement with these studies, we found no correlation between $\mathbf{V}$ and cell size (Figure S4).

\section{Discussion}

Here we presented a method to extract nuclear import and export rates that is suitable even from noisy single cell data. This method, based on the FRAP technique, consists of 
microscope procedures, routines for data processing, an ODE model to fit to the data, and algorithms for parameter optimization and error estimation. The results revealed large differences among cells in the fluxes in and out of their nuclei. We attribute this variability to differences in the number and/or quality of the nuclear pores. This is an unforeseen source of cell-to-cell variability, which might impact on several cellular processes that required directly or indirectly communication between these compartments.

\section{Using FRAP to measure transport rates}

FRAP experiments are usually analyzed by measuring fluorescence in the photobleached area, averaging data over several experiments, followed by fitting this average to a mathematical model- often just an exponential decay function- (for example, (Stevenson et al., 1995; Sprague and McNally, 2005; Fonseca et al., 2012; Huranová et al., 2010; Sekiya et al., 2009; Rino et al., 2008; Molenaar et al., 2004; Shav-Tal et al., 2004)). This approach is relatively simple and fast and might be sufficient for many purposes, but it does not take full advantage of a FRAP experiment. First, by measuring only the photobleached area, valuable data of the rest of the cell is lost. As we show here, by incorporating it into the mathematical model, this data may be used in the analysis. In addition, the bleached area is often small and thus the measurements are noisy. Second, averaging cells discards all single cell information and implicitly assumes that the "average cell" is representative of the population, which is often not the case (for example, (Novick and Weiner, 1957; Ferrell and Machleder, 1998)).Thus, this assumption could lead to erroneous results. Finally, fitting the data to an exponential curve gives only one parameter (the time constant tau) when, as illustrated here, it is possible to extract two well-defined and biologically meaningful parameters.

We showed that a simple two-parameter model maybe used to describe the data accurately independently of the transport mechanism of the studied protein. More complex models that include a more detailed mechanistic description of the transport process could certainly be correct, but they will likely have parameter identifiability problems.

We rationally designed an experimental protocol that in our case resulted in high quality data (good enough to obtain well determined parameters) even with signal to noise ratios as low as 5. Two main conclusions from our study leading to the final protocol design were responsible for the improvement in results: an increase in the time resolution -at the cost of noisier data-, and the use of more than one FRAP in each cell. In addition, we performed several the microscopy-related controls that led to corrections on the data, including imaging photobleaching and reversible photobleaching, often neglected but that may have significant effects on the results. In our case, reversed photobleaching was minimal, but the imaging photobleaching was significant. Remarkably, we found that photobleaching reversibility is impaired in paraformaldehyde-fixed cells and thus should not be studied in this condition, as it is usually done (Carrero et al., 2003).

For the optimization of parameters, we implemented a chi-square cost function that allows the statistical evaluation of the significance of the fittings. We have analyzed the 
identifiability of our parameters and found confidence intervals for them exploiting the likelihood profile analysis.

\section{Nuclear transport rates and parameter interpretation}

Using this method we calculated nuclear transport rates of fluorescent proteins in vivo and in single cells, $\mathbf{k I}$ and $\mathbf{k E}$, as well as the ratio between the cytosol and the nucleosol, $\mathbf{V}$. This is the ratio of volumes not occupied by organelles or macromolecules that is effectively available to the studied proteins. This number is needed in any mathematical model that includes these two compartments and it would be very difficult to measure by other methods. According to our data $\mathbf{V}$ is on average 4.8. Our result obtained by the FRAP method is consistent with our estimate based on the volume occupied by several organelles as determined using soft $X$ ray microscopy(Uchida et al., 2011). Not including the ER and large macromolecules complexes, this calculation results in a ratio of approximately 8 . Also, our number agrees well with electron microscopy based estimations of the nuclear volume/ cell volume of 6.25 (Webster et al., 2010).

A conclusion regarding our measurements of the transport rates is that the translocation through the nuclear pores is significantly slower than expected from previous in vitro essays (maximal capacity). The rates of transport determined by us are in the order of 0.1 $\mathrm{sec}^{-1}$. This number means that, if there are 1000 molecules of a given protein $\mathrm{X}$ in the cytosol (approximately $1 \mu \mathrm{M}$ ), and we assume that there are 86 nuclear pore complexes (Winey et al., 1997), then only 1.5 molecules of X are imported to the nucleus per second per pore. Our results are entirely compatible with the estimations of 3.3 molecules of GFP exported per pore per second for a $1 \mu \mathrm{M}$ gradient across the nuclear envelope in isolated oocytes nuclei (Siebrasse and Peters, 2002), the 0.18 NLS-GFP molecules imported NPC-1 sec-1per pore per second in yeast nuclei (Timney et al., 2006), the approximately 1 for GGNLS (Nemergut and Macara, 2000) in HeLa cells, and the 2 for GFP per pore per second for a $1 \mu \mathrm{M}$ gradient also in HeLa cells (Ribbeck and Gorlich, 2001). Remarkably, even though these studies were performed in different cells, the numbers agree. Nevertheless, comparison between them is complicated because of the different experimental conditions. If the transport rates prove to be so similar, this would imply that NPC permeability has been strongly conserved. Also, some of these measurements were done in permeabilized HeLa cells. These conditions are different to ours because they used very high concentrations of the studied transport cargo and most of the other cargoes were removed. In a functioning cell, it is expected that various transport pathways will compete with each other for the binding sites at the NPC.

Therefore, removing other cargoes should boost the transport of the studied cargo. As a consequence, it would be expected that the in vitro assays would result in higher transport rates. Again, standard measurements are needed, but if this proved to be true would undermine the idea of competition for the passive transport.

\section{Cell-to-cell variations in nuclear transport}

We found large cell-to-cell variation on the transport rates for YFP. Since YFP passes passively through the nuclear pores, in principle this large variability could be due to significant cell-to-cell differences in the number of nuclear pores or in their permeability. 
The number of NPC per cell has been counted by Winey et al -using the same strain and cell cycle position than we used - to be $86+-16$ (CV=0.19, ten cells)(Winey et al., 1997). This CV is too small to account for the variability we found, $\mathrm{CV} \sim=0.96$. Thus, we suspect that that the number of nuclear pores only contributes with a small part of the cell-to-cell variation observed, and we thus speculate that there must be a big variability in the permeability of the pores. Independently from the molecular source, this huge variability in nuclear transport capacity might affect the transport of every molecule and could have physiological consequences

In conclusion, we presented a method for the determination of import and export rates in single cells that can be applied to a wide range of systems in a standardized fashion. We believe that our results complement others on the study of nuclear transport. We showed that the number of translocations per NPC and per sec in live cells in normal conditions are lower than expected from in vitro studies, probably due to competition between different cargoes. Also, we found that populations exhibit large variability in nuclear transport rates. We hope these results will stimulate future studies on single cells kinetics.

Materials and Methods

Strains and plasmids

We performed general molecular biology procedures, yeast strain manipulation and construction according to previously established methods (Ausubel et al, 1987-2006; Guthrie \& Fink, 1991)

All strains generated and used in this study are listed in Table 1. Tagging of Myo1 with mCherry was performed by homologous recombination by transforming the appropriate strains with a PCR fragment containing mCherry followed by a hygromycin resistance cassette, flanked by 40 nucleotides of homology with the end of the MYO1 ORF (except the STOP codon) on its $5^{\prime}$ end and the region of the 3' UTR from +50 to +90 . We used as template for this PCR plasmid Pry2 2060.1 Hyg (Table 2) with the following primers:

Myo1-mCherry-for:

(AAATATTGATAGTAACAATGCACAGAGTAAAATTTTCAGTATGGCAACTAGCGGCATGGTT) and

Myo1-mCherry-rev:

(GTTAATAATGCATATTCTCATTCTGTATATACAAAACATCATAGGCCACTAGTGGATCTG ).

We selected transformants in plates with YPD plates with hygromycin and confirmed that integration occurred in the right location by visual determination of the presence of the red fluorescent ring at the bud-neck. 
Durrieu et al. Quantification of nuclear transport in single cells

All plasmids generated and used in this study are listed in Table 2.

\section{Cells preparation and microscopy}

Yeast cells were prepared for the experiments by growing them at least two consecutive days on selective BSM-TRP,LEU,URA $2 \%$ glucose plates. Then yeast from the least grown part of a streak were picked, resuspended in BSM-TRP,LEU,URA2\% glucose liquid media and added to a 384-well glass bottom plates (MGB101-1-1-LG, Matrical Biosciences). To prevent cells from moving, we pretreated the wells with concanavalin A (type V; SigmaAldrich, St. Louis, MO). To do this, we added to each well $50 \mathrm{ul}$ of a $100 \mathrm{mg} / \mathrm{ml}$ solution of concanavalin A in water, incubated at least for $20 \mathrm{~min}$ at room temperature (18-23 1C), and then washed 2 times with water. Cells were allowed to settle on the plate for 10-20 min and then we removed the supernatant and added $50 \mu \mathrm{l}$ of fresh selective medium.

To acquire images we used an Olimpus IX-81 inverted microscope with a FV1000 confocal module with an oil immersion Olympus UplanSapo 63X objective (numerical aperture, NA 1.35). For the experiments we used an automatic $z$-axis control, a motorized $x-y$ stage, a 458-488-515 argon and a 543 He-Ne lasers, and Hamamatsu R6353 photomultipliers (PMTs).

For a detailed description of the protocols for image acquisition, data correction and fitting, see the supplementary materials.

Box 1- a linear model follows from the assumption of initial steady-state

Let $\mathrm{N}$ be the total number of molecules in the cell, both fluorescent and bleached, of our protein of interest. Let $\mathrm{N}_{\mathrm{c}}$ denote the cytosolic fraction, and $\mathrm{N}_{\mathrm{n}}$ the nuclear fraction. At steady state these fractions remain constant so that the flux of molecules leaving the cytosol and entering the nucleus, $\mathrm{R}_{\mathrm{I}}$, is constant in time and exactly as big as the flux of molecules leaving the nucleus, $\mathrm{R}_{\mathrm{E}}$. Assume that the system is in such a steady state.

Let the superscripts ${ }^{\mathrm{b}}$ and ${ }^{\mathrm{f}}$ denote the fractions of $\mathrm{N}$ that are bleached and fluorescent respectively. In other words, $\mathrm{R}^{\mathrm{b}}$ denotes the flux of fluorescent molecules that are entering the nucleus. Since a molecule is either bleached or fluorescent, the flux in the direction $x, R_{x}$, is the sum of the flux for the bleached and fluorescent fractions respectively, $R=R_{x}+R_{x}$.

Assume that the bleached and fluorescent molecules are equal in all matters except detection, e.g. that they are homogenously mixed in the compartment they occupy, that they have equal affinity for the transporter, whether passive or active, etc. With this assumption it follows that a specific fluorescent molecule in the cytosol is, on average, equally likely to 
enter the nucleus as another specific non-fluorescent molecule in the cytosol. In other words, the fraction of the fluorescent and non-fluorescent fluxes will be exactly given by the fraction of fluorescent and non-fluorescent molecules in the compartment from which the flux flows.

$\mathrm{R}_{\mathrm{I}}=\mathrm{N}_{\mathrm{c}} / \mathrm{N}_{\mathrm{c}}, * \mathrm{R}_{\mathrm{I}}$

$\mathrm{R}_{\mathrm{E}}=\mathrm{N}_{\mathrm{n}} / \mathrm{N}_{\mathrm{n}}, * \mathrm{R}_{\mathrm{E}}$

Note that (2) and (3) hold independently of the kinetic equations for the original flux terms $\mathrm{R}_{\mathrm{I}}$ and $\mathrm{R}_{\mathrm{E}}$. Also assume that any spontaneous conversion between fluorescent and nonfluorescent molecules can be neglected. Then the differential equations for the fluorescent molecules are given by

$$
\begin{aligned}
& \mathrm{d} / \mathrm{dt}\left(\mathrm{N}_{\mathrm{c}}\right)=-\mathrm{R}_{\mathrm{I}}+\mathrm{R}_{\mathrm{E}}=-\mathrm{N}_{\mathrm{c}} / \mathrm{N}_{\mathrm{c}}, * \mathrm{R}_{\mathrm{I}}+\mathrm{N}_{\mathrm{n}} / \mathrm{N}_{\mathrm{n}}, * \mathrm{R}_{\mathrm{E}}=-\mathrm{k}_{\mathrm{I}} * \mathrm{~N}_{\mathrm{c}}+\mathrm{k}_{\mathrm{EV}} * \mathrm{~N}_{\mathrm{n}} \\
& \mathrm{d} / \mathrm{dt}\left(\mathrm{N}_{\mathrm{n}}\right)=\mathrm{R}_{\mathrm{I}}-\mathrm{R}_{\mathrm{E}}=\mathrm{N}_{\mathrm{c}} / \mathrm{N}_{\mathrm{c}} * \mathrm{R}_{\mathrm{I}}-\mathrm{N}_{\mathrm{n}} / \mathrm{N}_{\mathrm{n}}, * \mathrm{R}_{\mathrm{E}}=\mathrm{k}_{\mathrm{I}} * \mathrm{~N}_{\mathrm{c}}-\mathrm{k}_{\mathrm{EV}} * \mathrm{~N}_{\mathrm{n}}
\end{aligned}
$$

where the first rewriting of the right hand-side of the ODEs made use of (2) and (3), and the second defined the two constants $\mathrm{k}_{\mathrm{i}}$ and $\mathrm{k}_{\mathrm{EV}}$. We name the second constant $\mathrm{k}_{\mathrm{EV}}$ and not $\mathrm{k}_{\mathrm{E}}$ since there is an inherent volume ratio between the compartments that enters into the fluxes. Note that eqs. (4) and (5) describe both the linear kinetics of equations in eq. (1), and provide a general formula for how the rate constants in eq (1) should be interpreted based on the original kinetics. Similar formulas for some special cases of kinetics R are derived in the Supplementary material.

All in all, without assuming anything behind the kinetics that regulates the import and export of the protein, the dynamics of the bleached and fluorescent fraction can be described by a simple two-compartment model using ordinary mass-action dynamics. Simulation tests showing in another way that this simplification holds can be found in the appendix.

End of BOX 1.

\section{Authors contributions}

LD performed most of the experiments, constructed the strains and some of the plasmids used in the study, performed modeling and data analysis. AB performed FRAPs and helped in the data analysis. LD, AB and ACL interpreted the data. RJ supervised DL and MG and performed the analysis with multiple shell models. DL performed the profile likelihood analysis, and the implementation with the local optimization algorithm; MG 
performed the analysis proving that a detailed mechanistic model is equivalent to a two state model; GC directed the theoretical aspects of the project. LD, GC and ACL conceived the project. LD, GC and ACL wrote the paper.

\section{Acknowledgements}

We are grateful to Valeria Levi, Alicia Grande, Ariel Chernomoretz, Alejandra Ventura, Ignacio Schor, Fabian Rudolf, and Roger Brent for feedback and advise. We also thank Rich Yu for providing plasmids. We are especially grateful to Linnea Järvstråt and Ulrike Münzner, who participated in different aspects of the modeling and parameter estimation work. Work at GC lab was funded by the Swedish Research Council and at ACL lab by grants PICT2005-33628, PICT2007-847 and PICT2010-2248 from the Argentine Agency of Research and Technology (ANPCyT) to ACL and grant 1R01GM097479-01, subaward 0000713502 from NIGMS-NIH.

References

Ausubel FM, Brent R, Kingston RE, Moore DD, Seidman JG, Smith JA, Struhl K (1987-2006) Current protocols in molecular biology., New York, N.Y.: John Wiley \& Sons, Inc.

Becskei, A., and Mattaj, I. W. (2005). Quantitative models of nuclear transport. Current Opinion in Cell Biology, 27-34.

Bizzarri, R., Cardarelli, F., Serresi, M., and Beltram, F. (2012). Fluorescence recovery after photobleaching reveals the biochemistry of nucleocytoplasmic exchange. Analytical and bioanalytical chemistry.

Cardarelli, F., Bizzarri, R., Serresi, M., Albertazzi, L., and Beltram, F. (2009). Probing nuclear localization signal-importin alpha binding equilibria in living cells. The Journal of biological chemistry 284, 36638-36646. 
bioRxiv preprint doi: https://doi.org/10.1101/001768; this version posted January 13,2014 . The copyright holder for this preprint (which was not certified by peer review) is the author/funder, who has granted bioRxiv a license to display the preprint in perpetuity. It is made available under aCC-BY-NC-ND 4.0 International license.

Durrieu et al. Quantification of nuclear transport in single cells

Cardarelli, F., Serresi, M., Albanese, A., Bizzarri, R., and Beltram, F. (2011). Quantitative analysis of Tat peptide binding to import carriers reveals unconventional nuclear transport properties. The Journal of biological chemistry 286, 12292-12299.

Cardarelli, F., Tosti, L., Serresi, M., Beltram, F., and Bizzarri, R. (2012). Fluorescent recovery after photobleaching (FRAP) analysis of nuclear export rates identifies intrinsic features of nucleocytoplasmic transport. The Journal of biological chemistry $287,5554-5561$.

Carrero, G., McDonald, D., Crawford, E., de Vries, G., and Hendzel, M. J. (2003). Using FRAP and mathematical modeling to determine the in vivo kinetics of nuclear proteins. Methods 29, $14-28$.

Chu, C. T., Plowey, E. D., Wang, Y., Patel, V., and Jordan-Sciutto, K. L. (2007). Location, location, location: altered transcription factor trafficking in neurodegeneration. Journal of neuropathology and experimental neurology 66, 873-883.

Colman-Lerner, A., Chin, T. E., and Brent, R. (2001). Yeast Cbk1 and Mob2 activate daughterspecific genetic programs to induce asymmetric cell fates. Cell 107, 739-750.

Colman-Lerner, A., Gordon, A., Serra, E., Chin, T., Resnekov, O., Endy, D., Pesce, C. G., and Brent, R. (2005). Regulated cell-to-cell variation in a cell-fate decision system. Nature 437, 699706.

Costa, M., Marchi, M., Cardarelli, F., Roy, A., Beltram, F., Maffei, L., and Ratto, G. M. (2006).Dynamic regulation of ERK2 nuclear translocation and mobility in living cells. Journal of Cell Science, 4952-4963.

Dohrmann, P. R., Butler, G., Tamai, K., Dorland, S., Greene, J. R., Thiele, D. J., and Stillman, D. J. (1992). Parallel pathways of gene regulation: homologous regulators SWI5 and ACE2 differentially control transcription of $\mathrm{HO}$ and chitinase. Genes Dev. 6, 93-104.

Ferrell, J. E., and Machleder, E. M. (1998). The biochemical basis of an all-or-none cell fate switch in Xenopus oocytes.Science 280, 895-898.

Fonseca, J. P., Steffen, P. A., Müller, S., Lu, J., Sawicka, A., Seiser, C., and Ringrose, L. (2012). In vivo Polycomb kinetics and mitotic chromatin binding distinguish stem cells from differentiated cells. Genes \& Development 26, 857-871.

Gordon, A., Colman-Lerner, A., Chin, T. E., Benjamin, K. R., Yu, R. C., and Brent, R. (2007). Singlecell quantification of molecules and rates using open-source microscope-based cytometry. Nat Methods 4, 175-181.

Gregor, T., Wieschaus, E. F., McGregor, A. P., Bialek, W., and Tank, D. W. (2007).Stability and nuclear dynamics of the bicoidmorphogen gradient. Cell 130, 141-152.

Görner, W., Schüller, C., and Ruis, H. (1999). Being at the right place at the right time: the role of nuclear transport in dynamic transcriptional regulation in yeast. BiolChem380, 147-150. 
Durrieu et al. Quantification of nuclear transport in single cells

Guthrie C, Fink GR (1991) Methods in Enzymology, Guide to Yeast Genetics and Molecular Biology, San Diego, California 92101: Academic Press.

Henderson, J. N., Ai, H.-wang, Campbell, R. E., and Remington, S. J. (2007). Structural basis for reversible photobleaching of a green fluorescent protein homologue. PNAS.

Huranová, M., Ivani, I., Benda, A., Poser, I., Brody, Y., Hof, M., Shav-Tal, Y., Neugebauer, K. M., and Stanek, D. (2010). The differential interaction of snRNPs with pre-mRNA reveals splicing kinetics in living cells. The Journal of Cell Biology 191, 75-86.

Jorgensen, P., Edgington, N. P., Schneider, B. L., Rupes, I., Tyers, M., and Futcher, B. (2007). The Size of the Nucleus Increases as Yeast Cells Grow.Molecular biology of the cell 18, 35233532.

Kahms, M., Hüve, J., Wesselmann, R., Farr, J. C., Baumgärtel, V., and Peters, R. (2011). Lighting up the nuclear pore complex. European Journal of Cell Biology 90, 751-758.

Keminer, O., and Peters, R. (1999). Permeability of single nuclear pores. Biophysical journal 77, 217-228.

Keminer, O., Siebrasse, J. P., Zerf, K., and Peters, R. (1999).Optical recording of signal-mediated protein transport through single nuclear pore complexes. Proceedings of the National Academy of Sciences of the United States of America 96, 11842-11847.

Khmelinskii A, Keller PJ, Lorenz H, Schiebel E, Knop M (2010) Segregation of yeast nuclear pores. Nature 466: E1.

Komeili, A., and O'Shea, E. K. (2000). Nuclear transport and transcription.CurrOpin Cell Biol12, 355-360.

Kubitscheck, U., Grünwald, D., Hoekstra, A., Rohleder, D., Kues, T., and Siebrasse, J. P. (2005). Dwell times at the nuclear pore complex. Cell 168, 233-243.

Lee, S.-H., and Hannink, M. (2003). Molecular mechanisms that regulate transcription factor localization suggest new targets for drug development. Advanced drug delivery reviews 55, 717-731.

Leslie, D. M., Timney, B., Rout, M. P., and Aitchison, J. D. (2006). Studying nuclear protein import in yeast. Methods (San Diego, Calif.) 39, 291-308.

Menendez-Benito V, van Deventer SJ, Jimenez-Garcia V, Roy-Luzarraga M, van Leeuwen F, Neefjes J (2013) Spatiotemporal analysis of organelle and macromolecular complex inheritance. Proc Natl Acad Sci U S A 110: 175-180.

Mohr, D., Frey, S., Fischer, T., Güttler, T., and Görlich, D. (2009). Characterisation of the passive permeability barrier of nuclear pore complexes. The EMBO journal 28, 2541-2553. 
Molenaar, C., Abdulle, A., Gena, A., Tanke, H. J., and Dirks, R. W. (2004). Poly(A)+ RNAs roam the cell nucleus and pass through speckle domains in transcriptionally active and inactive cells. The Journal of Cell Biology 165, 191-202.

Nemergut, M. E., and Macara, I. G. (2000). Nuclear import of the ran exchange factor, RCC1, is mediated by at least two distinct mechanisms. The Journal of Cell Biology 149, 835-850.

Novick, A., and Weiner, M. (1957). Enzyme induction as an all-or-non phenomenon. ProcNatlAcadSci U S A 43, 553-556.

O'Brate, A., and Giannakakou, P. (2003). The importance of p53 location: nuclear or cytoplasmic zip code? Drug resistance updates : reviews and commentaries in antimicrobial and anticancer chemotherapy 6, 313-322.

Paine, P., and Scherr, P. (1975). Drag coefficients for the movement of rigid spheres through liquid-filled cylindrical pores. Biophys.J. 15, 1087-1091.

Pfeifer, A. C., Kaschek, D., Bachmann, J., Klingmüller, U., and Timmer, J. (2010).Model-based extension of high-throughput to high-content data. Stat.

Poon, I. K. H., and Jans, D. A. (2005). Regulation of Nuclear Transport : Central Role in Development and Transformation ? Traffic, 173-186.

Ribbeck, K., and Gorlich, D. (2001). Kinetic analysis of translocation through nuclear pore complexes. EMBO J. 20, 1320-1330.

Riddick, G., and Macara, I. G. (2005). A systems analysis of importin-\{alpha\}-\{beta\} mediated nuclear protein import. The Journal of Cell Biology 168, 1027-1038.

Rino, J., Desterro, J. M. P., Pacheco, T. R., Gadella, T. W. J., and Carmo-Fonseca, M. (2008). Splicing factors SF1 and U2AF associate in extraspliceosomal complexes. Molecular and Cellular Biology 28, 3045-3057.

Rout, M. P., Aitchison, J. D., Suprapto, a, Hjertaas, K., Zhao, Y., and Chait, B. T. (2000). The yeast nuclear pore complex: composition, architecture, and transport mechanism. The Journal of Cell Biology 148, 635-651.

Shcheprova Z, Baldi S, Frei SB, Gonnet G, Barral Y (2008) A mechanism for asymmetric segregation of age during yeast budding. Nature 454: 728-734

Sekiya, T., Muthurajan, U. M., Luger, K., Tulin, A. V., and Zaret, K. S. (2009).Nucleosome-binding affinity as a primary determinant of the nuclear mobility of the pioneer transcription factor FoxA.Genes \& Development 23, 804-809.

Shav-Tal, Y., Darzacq, X., Shenoy, S. M., Fusco, D., Janicki, S. M., Spector, D. L., and Singer, R. H. (2004). Dynamics of single mRNPs in nuclei of living cells. Science (New York, N.Y.) 304, 1797-1800. 
bioRxiv preprint doi: https://doi.org/10.1101/001768; this version posted January 13,2014 . The copyright holder for this preprint (which was not certified by peer review) is the author/funder, who has granted bioRxiv a license to display the preprint in perpetuity. It is made available under aCC-BY-NC-ND 4.0 International license.

Durrieu et al. Quantification of nuclear transport in single cells

Siebrasse, J. P., and Peters, R. (2002). Rapid translocation of NTF2 through the nuclear pore of isolated nuclei and nuclear envelopes. EMBO reports 3, 887-892.

Sinnecker, D., Voigt, P., Hellwig, N., and Schaefer, M. (2005). Reversible Photobleaching of Enhanced Green Fluorescent Proteins †. Culture 3, 7085-7094.

Spencer, S. L., Gaudet, S., Albeck, J. G., Burke, J. M., and Sorger, P. K. (2009).Non-genetic origins of cell-to-cell variability in TRAIL-induced apoptosis.Nature 459, 428-432.

Sprague, B. L., and McNally, J. G. (2005). FRAP analysis of binding: proper and fitting. Trends in cell biology 15, 84-91.

Stevenson, B. J., Ferguson, B., De Virgilio, C., Bi, E., Pringle, J. R., Ammerer, G., and Sprague Jr., G. F. (1995). Mutation of RGA1, which encodes a putative GTPase-activating protein for the polarity-establishment protein Cdc42p, activates the pheromone- response pathway in the yeast Saccharomyces cerevisiae. Genes Dev. 9, 2949-2963.

Timney, B. L., Tetenbaum-Novatt, J., Agate, D. S., Williams, R., Zhang, W., Chait, B. T., and Rout, M. P. (2006). Simple kinetic relationships and nonspecific competition govern nuclear import rates in vivo. The Journal of Cell Biology 175, 579-593.

Uchida, M., Sun, Y., Mcdermott, G., Knoechel, C., Gros, M. A. L., Parkinson, D., Drubin, D. G., and Larabell, C. A. (2011). Quantitative analysis of yeast internal architecture using soft X-ray tomography. Yeast, 227-236.

Wagner, A. (2005). Energy constraints on the evolution of gene expression.Molecular biology and evolution 22, 1365-1374.

Webster, M. T., McCaffery, J. M., and Cohen-Fix, O. (2010). Vesicle trafficking maintains nuclear shape in Saccharomyces cerevisiae during membrane proliferation. The Journal of Cell Biology 191, 1079-1088.

Weiss, E. L., Kurischko, C., Zhang, C., Shokat, K., Drubin, D. G., and Luca, F. C. (2002). The Saccharomyces cerevisiae Mob2p-Cbk1p kinase complex promotes polarized growth and acts with the mitotic exit network to facilitate daughter cell-specific localization of Ace $2 p$ transcription factor. J Cell Biol158, 885-900.

Winey, M., Yarar, D., Giddings, T. H., and Mastronarde, D. N. (1997). Nuclear pore complex number and distribution throughout the Saccharomyces cerevisiae cell cycle by threedimensional reconstruction from electron micrographs of nuclear envelopes. Molecular biology of the cell 8, 2119-2132.

Yang, W., Gelles, J., and Musser, S. M. (2004). Imaging of single-molecule translocation through nuclear pore complexes. PNAS 101, 12887-12892.

Yang, W., and Musser, S. M. (2006). Nuclear import time and transport efficiency depend on importin beta concentration. The Journal of cell biology 174, 951-961. 
bioRxiv preprint doi: https://doi.org/10.1101/001768; this version posted January 13,2014 . The copyright holder for this preprint (which was not certified by peer review) is the author/funder, who has granted bioRxiv a license to display the preprint in perpetuity. It is made available under aCC-BY-NC-ND 4.0 International license.

Durrieu et al. Quantification of nuclear transport in single cells

\section{Figure legends}

Fig 1. Performing train of FRAPs allows to extract the parameters even in low signal-to-noise conditions. (a) Schematic of an essay with a train of 2 partial FRAPs. (b) Parameters obtained from fitting simulated data of trains of different amounts of FRAPS. The gray line shows the parameter real value $\left(0.4 \mathrm{sec}^{-1}\right)$. Accuracy of the determined transport rates as a function of the number of FRAPs per train. Upper: Simulated data with a signal-to-noise ratio of 5. Notice that with 4 FRAPs the parameter is recovered consistently. Lower: Simulated data with a signal-to-noise ratio of 50, the parameter is recovered precisely even with a train of 2 FRAPs. (c) Fitting the train of 4 FRAPs is better than fitting the average of the 4 individual FRAPs. Data corresponds to the analysis of ten simulated cells for each noise level. Only kI is shown, but the same was observed for $\mathrm{kEV}$. The gray line shows the parameter real value $\left(0.4 \mathrm{sec}^{-1}\right)$. Left: Simulated data with a signal-to-noise ratio of 50. Right: Simulated data with a signal-to-noise ratio of 5.

Figure 2. Performing train of FRAPs allows us to get the import and export rates with small errors.a, Time course showing the first FRAP in a train of 4 FRAPs experiment. The first picture shows CFP-ACE2, which is used to find the nucleus and determine the cell cycle position. The rest of the strip shows un-fused YFP. The frames displayed are separated by $0.44 \mathrm{sec}$, but actual time resolution is 0.22 . b, Example of the exploration of the parameter space in the fitting of a train of FRAPs experiment. Black points represent evaluated combinations of the parameters, red points represents parameter pairs which cost was considered acceptable. Three points are highlighted with a diamond: in blue, the optimal parameters pair, in green, the worst acceptable pair and in cyan, a very bad pair. c, Example of experimental data and fittings. The black line depicts the data, the gray shading shows the signal noise, the blue line is the optimal fit and the other lines correspond to simulations with the parameter pairs depicted in the same color in (b). d, Likelihood profile analysis. The dotted line is the cut-off, calculated as the lowest cost + chi2 for one degree and $95 \%$ confidence $(3.84)$.

Figure 3. Nuclear transport rates of YFP exhibit large cell-to-cell variation. (a) Single-cells rates of nuclear transport in strain BY4741. The black dots indicate individual cells, the red asterisk shows the mean. (b) Same for strain W303. (c) Import rate as a function of the average YFP expression level in the cell for BY4741 strain.

Figure 4. The cytosol/nucleosol diffusion-available volumes ratio is similar in strains W303 and BY4741. Data for each strain comes from un-fused YFP trains of FRAPs experiments on at least 50 cells. 
Figure S1. FRAP recovery in the cytosol is faster than in the nucleus. Comparison of the recovery times after photobleaching was induced in the nucleus (blue) or in the cytosol (red). Pictures were taken every 0.22 secs.

Figure S2. Nuclear transport rates determination accuracy depends on the signal to noise ratio of the data. Fitted parameters $(\mathrm{tau}=1 /(\mathrm{kI}+\mathrm{kEV}))$ as a function of the signalto-noise ratio. Simulated data of a single FRAP essay with snr from 1 to 100 was fitted as experimental data ( 10 cells for each level of noise). The gray dotted line shows the true value. The parameters from datasets with snr lower than 50 were recovered poorly.

Figure S3. Individual data and fits for all the BY4741 wt cells obtained. Experimental data dynamics and noise levels vary, but fits are robust.

Figure S4. The nucleus/cytosol diffusion-available volumes (V) do not depend on the cell size. $\mathrm{V}$ is plot against cell area as an indicator for cell size. No correlation between the variables was observed. 
bioRxiv preprint doi: https://doi.org/10.1101/001768; this version posted January 13,2014 . The copyright holder for this preprint (which was not certified by peer review) is the author/funder, who has granted bioRxiv a license to display the preprint in perpetuity. It is made available under aCC-BY-NC-ND 4.0 International license.

Figure 1

A
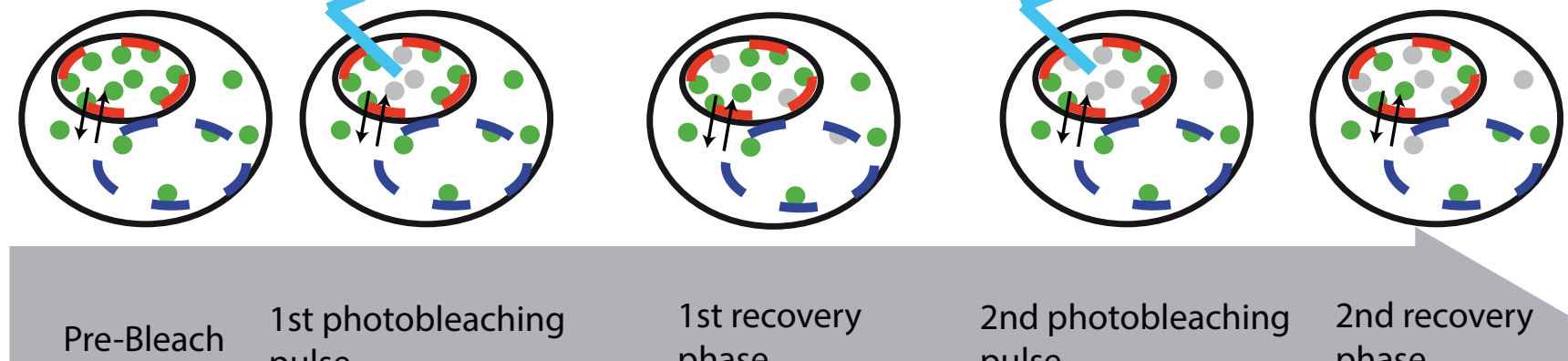

1st photobleaching pulse

1st recovery phase

2nd photobleaching pulse

2nd recovery phase
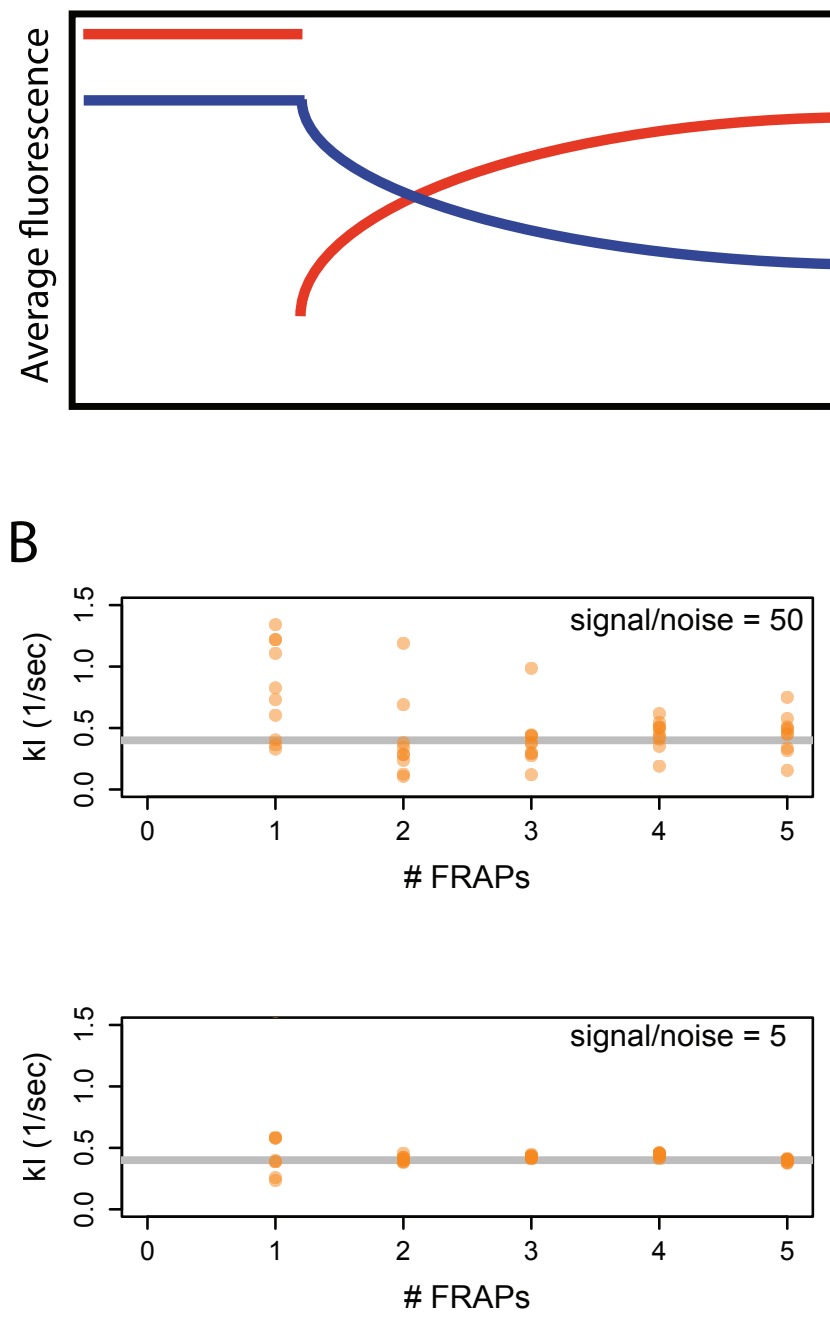

C
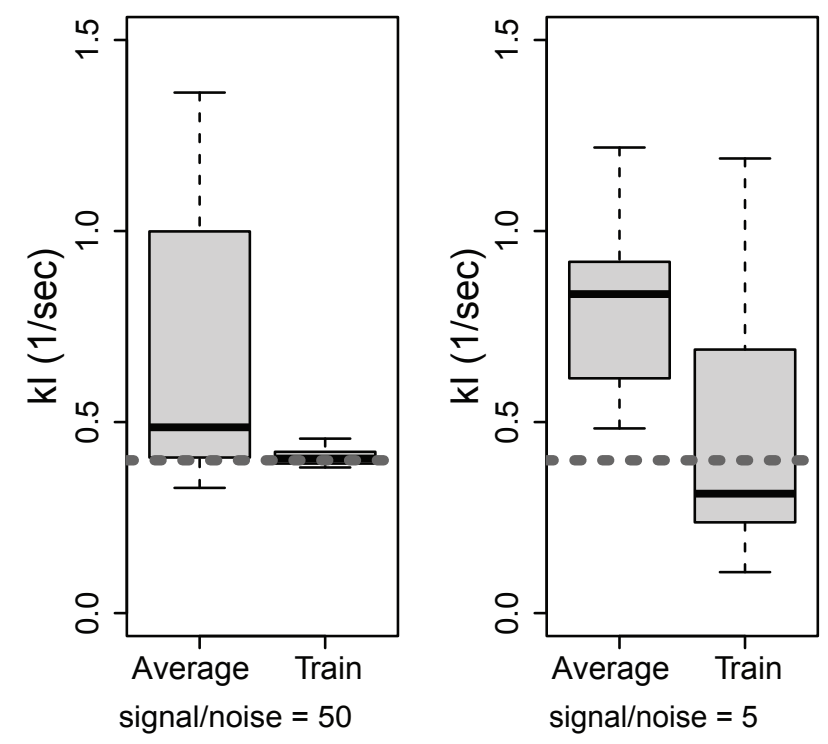


\section{Figure 2}

A bioRxiv preprint doi: https://doi.org/10.1101/001768; this version posted January 13, 2014. The copyright holder for this preprint (which was not certified by peer review) is the author/funder, who has granted bioRxiv a license to display the preprint in perpetuity. It is made available under aCC-BY-NC-ND 4.0 International license.

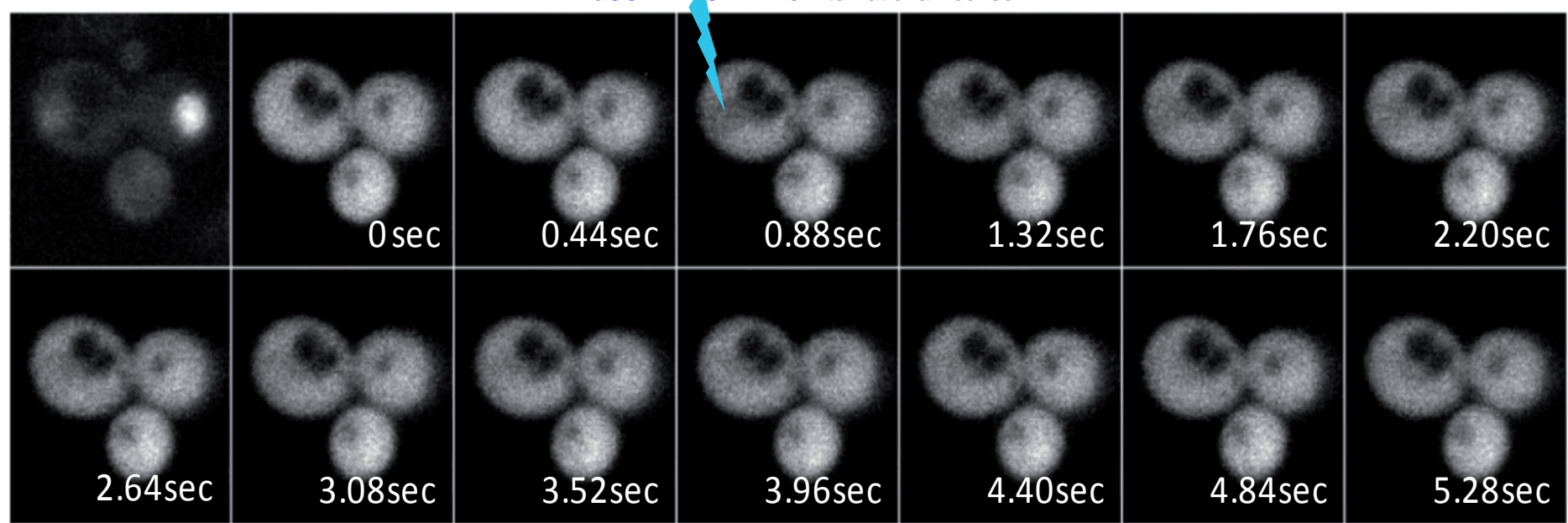

B
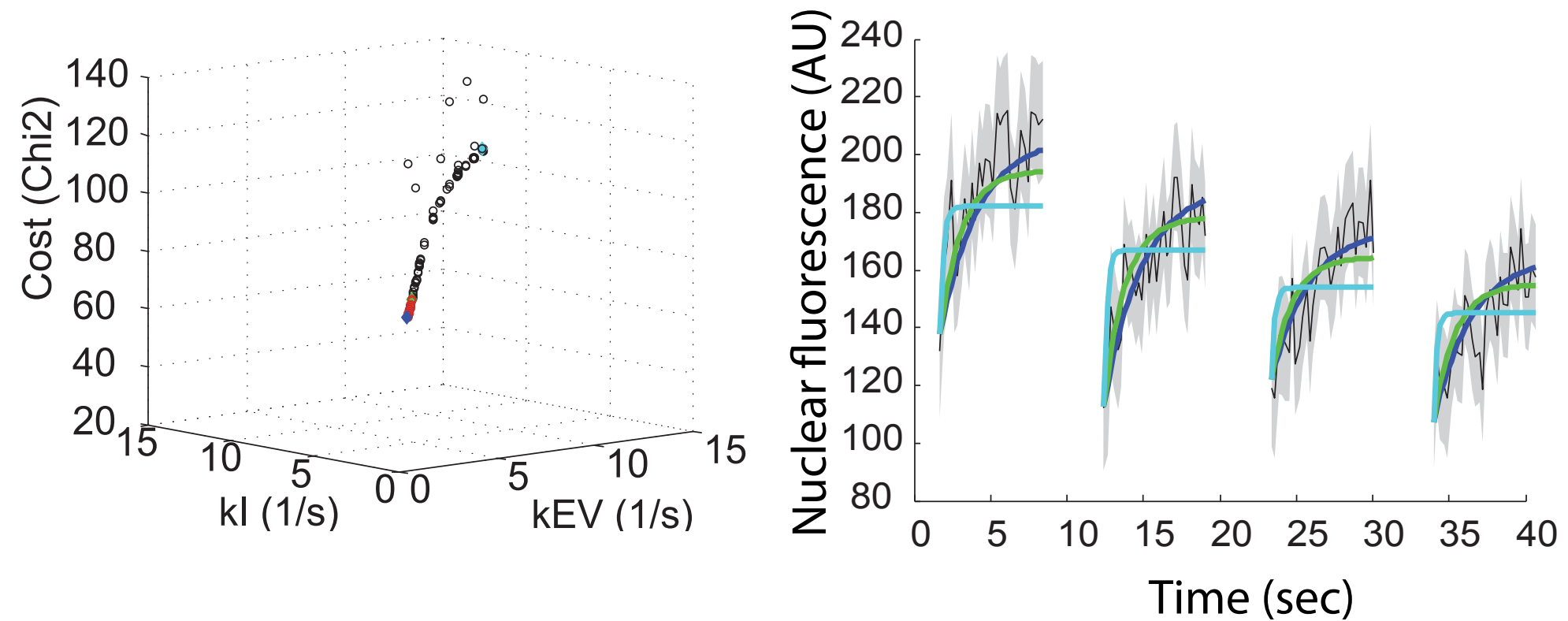

D
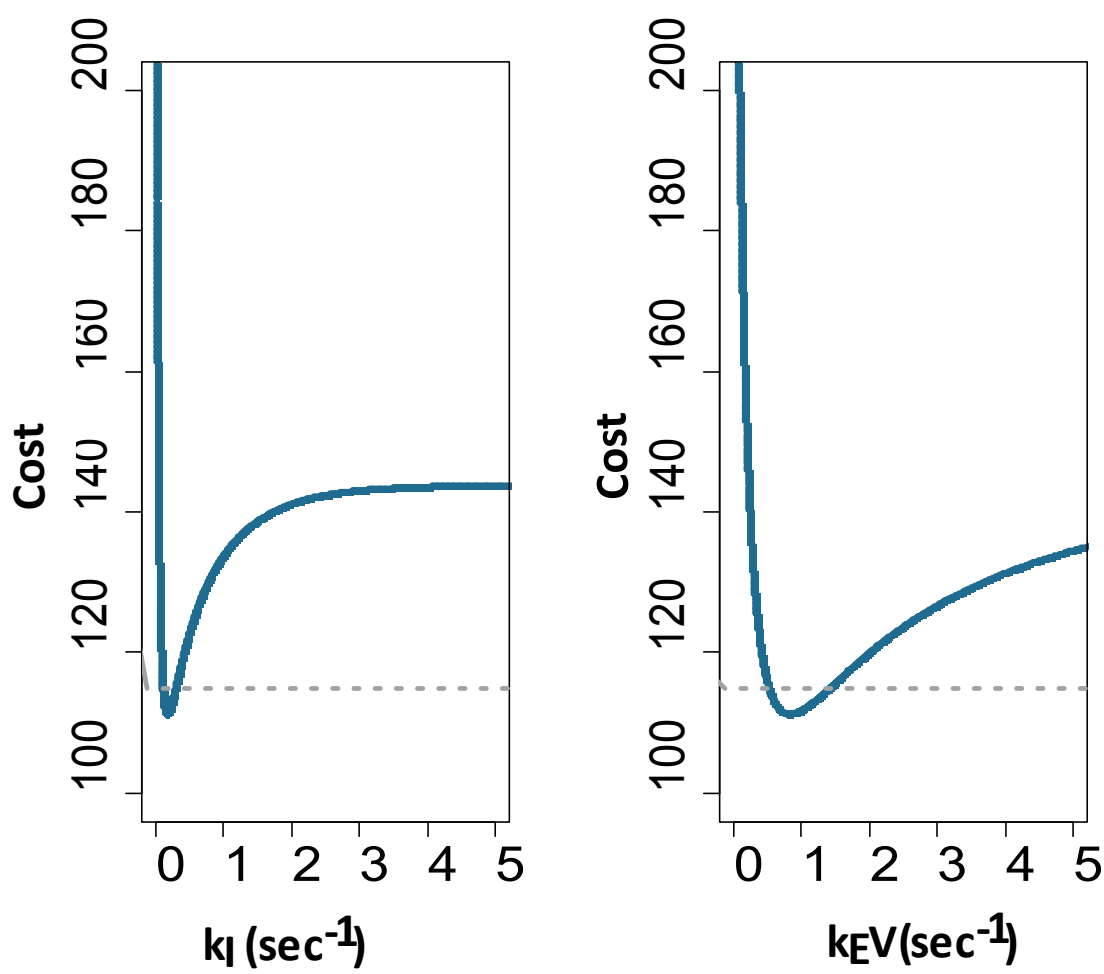
Figure 3

A bioRxiv preprint doi: https://doi.org/10.1101/001768; this version posted January 13, 2014. The copyright holder for this preprint (which was not certified by peer review) is the author/funder, who has granted bioRxiv a license to display the preprint in perpetuity. It is made available under aCC-BY-NC-ND 4.0 International license.

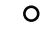

$+--\square \square$ O

00

$\circ \circ$
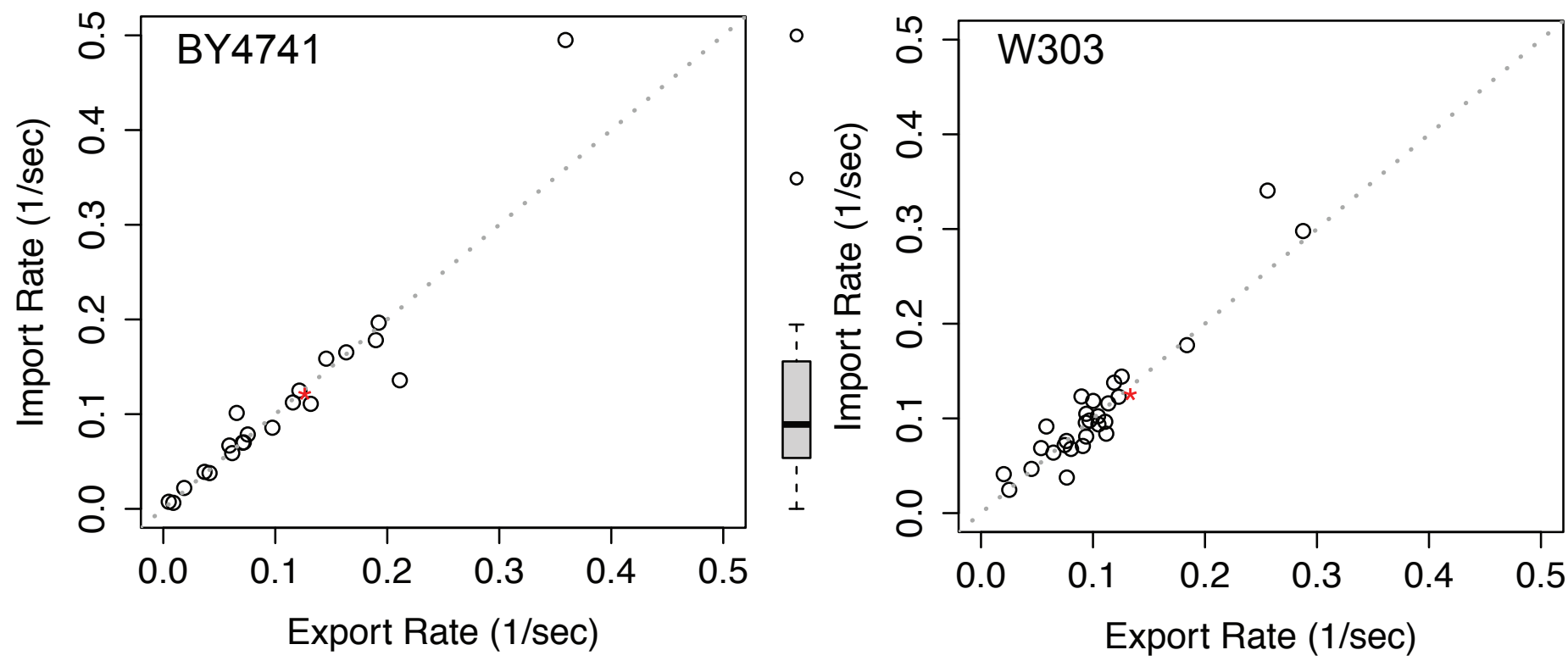

C

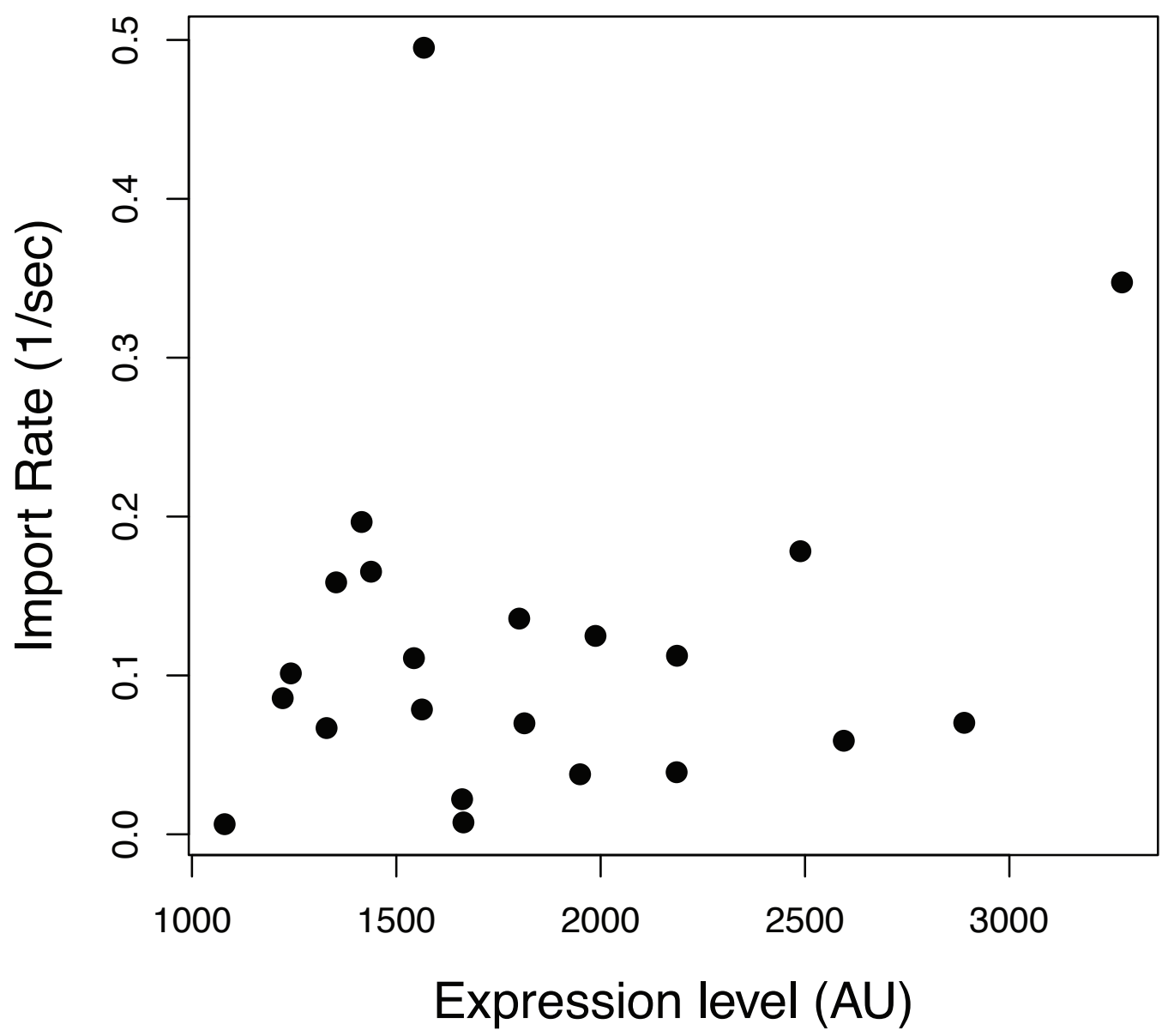


Figure 4

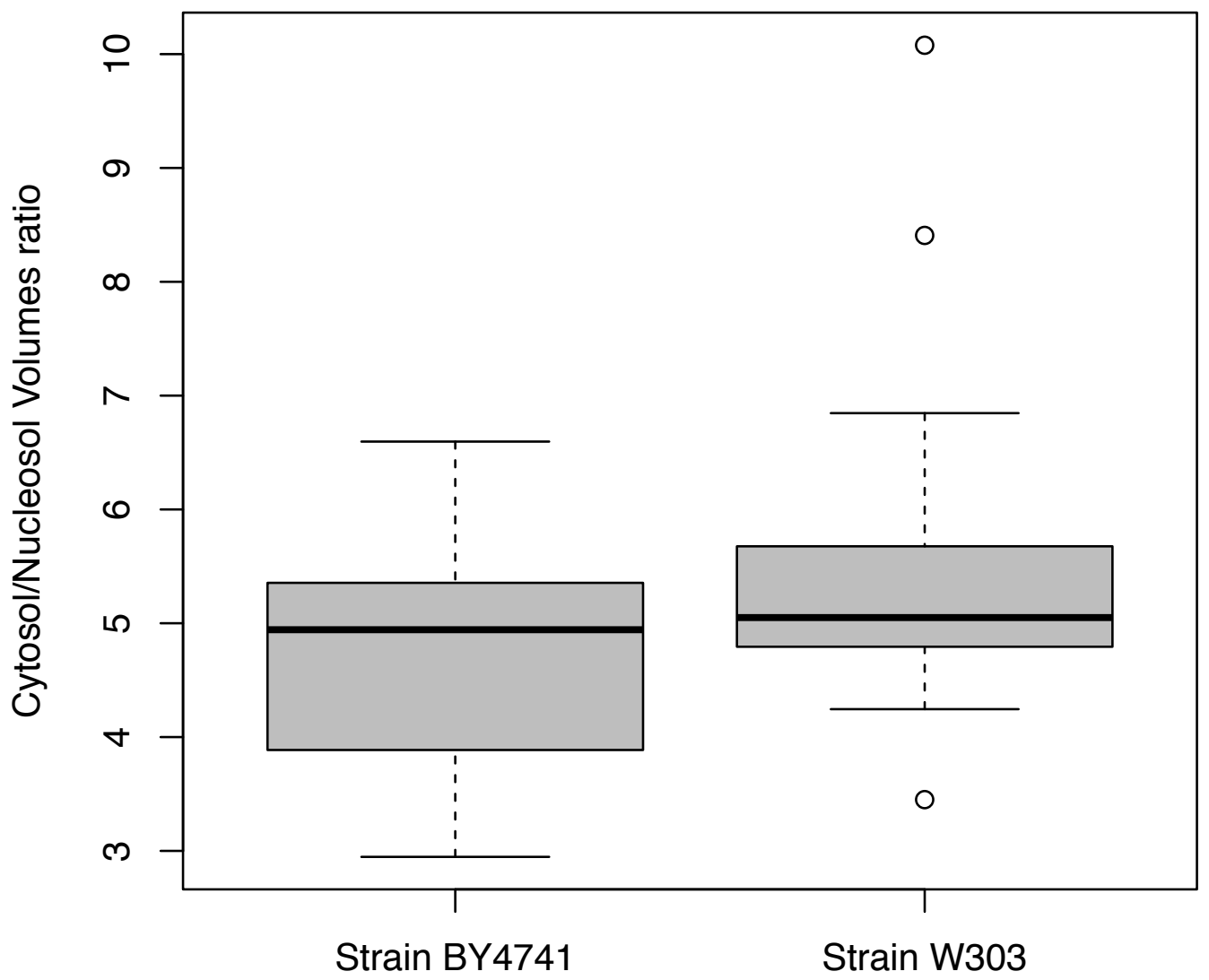

